\title{
Optimizing the Extraction of Anthocyanins from the Skin and Phenolic Compounds from the Seed of Jabuticaba Fruits (Myrciaria jaboticaba (Vell.) O. Berg) with Ternary Mixture Experimental Designs
}

\author{
Michelly C. Paludo, ${ }^{a}$ Ronan C. Colombo, ${ }^{b}$ José Teixeira Filho, ${ }^{c}$ \\ Isidro Hermosín-Gutiérrez, ${ }^{d}$ Cristiano A. Ballus ${ }^{e}$ and Helena T. Godoy ${ }^{\circledR *, a}$ \\ ${ }^{a}$ Departamento de Ciência de Alimentos, Faculdade de Engenharia de Alimentos, \\ Universidade Estadual de Campinas (UNICAMP), Rua Monteiro Lobato, 80, \\ 13083-862 Campinas-SP, Brazil \\ ${ }^{b}$ Centro de Pesquisa Agrícola, Universidade Estadual de Londrina, \\ Rodovia Celso Garcia Cid, km 380, 86057-970 Londrina-PR, Brazil \\ ${ }^{c}$ Faculdade de Engenharia Agrícola, Universidade Estadual de Campinas (UNICAMP), \\ Avenida Cândido Rondon, 501, 13083-875 Campinas-SP, Brazil \\ ${ }^{d}$ Instituto Regional de Investigación Científica Aplicada, Universidad de Castilla-La Mancha, \\ Campus Universitario s/n, 13071 Ciudad Real, Spain \\ ${ }^{e}$ Departamento de Tecnologia e Ciência dos Alimentos, Centro de Ciências Rurais, \\ Universidade Federal de Santa Maria, Avenida Roraima, 1000, 97105-900 Santa Maria-RS, Brazil
}

\begin{abstract}
Total phenolic compounds (TPC) extraction from the seed and total monomeric anthocyanins (TMA) extraction from the skin of "Sabará" jabuticaba were optimized with simplex lattice designs for solvent mixing, and the extraction time was optimized by univariate design. The optimum conditions for the extraction method were ethanol:water $(60: 40 \mathrm{v} / \mathrm{v})$ solvent for TPC (seed) and methanol:water:acetic acid (80:20:0.5 v/v/v) solvent for TMA (skin). For both compound groups, the optimum extraction time was $30 \mathrm{~min}$. The TMA yield for the skin of the "Sabará" variety was $1172.16 \mathrm{mg}$ cyanidin-3-glycoside equivalents per $100 \mathrm{~g}$ freeze-dried sample, and for TPC in the seed, it was $86.50 \mathrm{mg}$ gallic acid equivalents per $1 \mathrm{~g}$ freeze-dried sample. Both optimized extraction protocols proved to be extremely fast, simple, inexpensive and to have excellent extraction performance. The optimized protocols were compared with two other methods described in the literature and they were also applied to study the TMA contents in skin and the TPC contents in seed of five other varieties of jabuticaba, harvested in 2014 and 2015.
\end{abstract}

Keywords: Myrciaria ssp., total monomeric anthocyanins, phenolic compounds, experimental design, optimization

\section{Introduction}

Jabuticaba is commonly found in Mata Atlântica, a Brazilian biome, but it can grow in a large variety of soils and environmental conditions. ${ }^{1}$ Due to the high yields, rusticity, high commercial value of fresh fruits and use in prepared juices, jellies, and other products, jabuticaba has aroused the interest of farmers. ${ }^{2}$ Jabuticaba fruit consists of a subgloboid-berry covered by a smooth and light darkpurple or black skin with one to four seeds in the flesh. ${ }^{3,4}$

*e-mail: helena@fea.unicamp.br
In addition, the fruit is rich in phenolic compounds that are found mainly in the skin. ${ }^{5}$

A progressive interest in studying the phenolic compound activity, especially the anthocyanins, in small fruits extracts has increased due to the positive correlation between consuming these fruits and decrease in cardiovascular problems ${ }^{6}$ and other chronic diseases. ${ }^{7}$ These compounds can act like primary antioxidants, reacting directly with free radicals and giving way to a less reactive radical than the initial free radical, or they can act as secondary antioxidants, restoring or enhancing other antioxidant systems. ${ }^{8}$ 
Anthocyanins are among the most well-known natural pigments and are functional compounds that add value to food. ${ }^{9}$ Additionally, they can be used as substitutes for synthetic food coloring in the food industry. ${ }^{10}$ Anthocyanins exhibit numerous biological activities, including anti-inflammatory, ${ }^{11}$ anti-cancer, ${ }^{12}$ anti-mutagenic, ${ }^{13}$ chemopreventive, ${ }^{14}$ and antiviral activity, ${ }^{15}$ among others.

Several methods of extraction for phenolic compounds, including anthocyanins, are found in the literature ${ }^{16}$ along with optimization of their extraction. ${ }^{17}$ However, few studies have focused specifically on optimizing the extraction of total phenolic compounds (TPC) of the jabuticaba seed and total monomeric anthocyanins (TMA) of the jabuticaba skin. Moreover, the great majority of the studies are based on the skin, and we only found one study that optimized the TPC extraction of the jabuticaba seed..$^{18}$ The available protocols for these purposes, even those that approached the optimization of the extraction method, require very long extraction times and processes not accessible to all laboratories.

It is known that the extraction stage of matrix compounds is one of the most important phases in the food analysis process because it is always preferable to extract the compounds of interest as selectively and exhaustively as possible. ${ }^{19}$ Thus, the use of experimental planning makes it possible to study extraction variables simultaneously. In addition, besides evaluating each individual variable, it is also possible to determine some synergistic and antagonistic effects resulting from the interactions among the studied variables. ${ }^{20}$

Keeping in mind that jabuticaba has high levels of phenolic compounds, especially anthocyanins, and that these compounds have beneficial effects, it is very important to develop a fast, simple, cheap and efficient method to extract these compounds.

Thus, this study aimed to optimize the extraction protocols for TPC from seed and TMA from the skin of the "Sabará" jabuticaba by multivariate experimental design with easily accessible solvents and simple methods. The optimized extraction protocols were then applied to five other jabuticaba varieties for the following determination of TPC and TMA.

\section{Experimental}

\section{Samples}

"Sabará" (Myrciaria jaboticaba (Vell.) O. Berg) (SF) and "Paulista" (Myrciaria cauliflora (DC.) O. Berg) (PF) jabuticaba samples were provided by Grupo de Produtores Rurais Fagan, located in Lagoa Branca,
São Paulo (21 ${ }^{\circ} 46^{\prime} 26^{\prime \prime} \mathrm{S}, 47^{\circ} 05^{\prime} 11^{\prime \prime} \mathrm{W}$ and $684 \mathrm{~m}$ of elevation) in October 2014 and 2015. Other samples of "Sabará" (Myrciaria jaboticaba (Vell.) O. Berg) (SFP), "Coroada" (Myrciaria coronata Mattos) (CFP), "Híbrida" (Myrciaria cauliflora (DC.) O. Berg) (HFP) and "Pintada" (Plinia ssp.) (PFP) jabuticabas were provided by F. P. Frutas e Plantas, located in Araçoiaba da Serra,

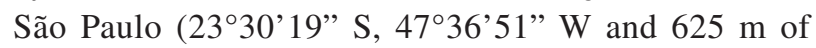
elevation) in October 2014 and 2015. Fruits samples were hand-processed to separate seed and skin, which were frozen at $-22{ }^{\circ} \mathrm{C}$, freeze-dried, vacuum-packed and stored at $-22{ }^{\circ} \mathrm{C}$. The freeze-dried samples were ground to a fine and homogeneous powder to be used to prepare the extracts.

Extraction optimization of TMA from skin and TPC from seed in "Sabará" jabuticaba (SF)

Evaluation of solvent effects by simplex lattice design (SLD)

The efficiency of the extraction with different proportions of solvents was studied aiming to determine the combination that produced more efficient extraction. Methanol, ethanol and water solvent mixtures were chosen to extract TPC from the jabuticaba seed and TMA from the jabuticaba skin because these solvents have been shown to produce efficient extraction, as demonstrated by previously published studies, ${ }^{21-24}$ and are accessible to all research laboratories.

The multivariate statistical technique for optimization of mixtures, simplex centroid design with axial points, allows analysis of all proportions of solvents (0-100\%) using a reduced number of experiments. In addition, it allows examination of possible interactions between the variables. ${ }^{25}$ All conditions tested are shown in Supplementary Information (SI) Table S1.

The different conditions studied in this trial form a triangle, with pure components at the vertex representing $100 \%$ of one of each solvent. Middle points in each side represent a binary mixture (1:1), the center point represents a ternary mixture (1:1:1), and axial points represent $2 / 3$ of one of the solvents and $1 / 6$ of the others. Thus, this kind of design allows the evaluation of linear and quadratic models of response. ${ }^{26}$

Jabuticaba variety "Sabará" (SF) was chosen to be used in the optimization experiments. Fifty $\mathrm{mL}$ of extraction solvent, in the proportion defined by the experimental mixture design, were added to $0.5 \mathrm{~g}$ of freeze-dried skin or seed samples, respectively. The only difference between the experimental design for seed and for skin was that, for the total monomeric anthocyanins extraction from the skin, $0.5 \%$ of acetic acid were added to all the mixtures of the experimental design. The mixture was shaken for 
$2 \mathrm{~h}$ in a shaking water bath at $30^{\circ} \mathrm{C}$, centrifuged, filtered in Whatman paper No. 1, and re-extracted two more times under the same conditions, using $25+25 \mathrm{~mL}$ of the extraction solvent in the proportions under study. The extracts obtained in the three extractions were combined, taken to a volume of $100 \mathrm{~mL}$ in a volumetric flask.

The TMA and TPC were the two evaluated responses, and the procedures are described in the sub-section below.

The solvent ratio that resulted in the optimal TMA response of the jabuticaba skin and TPC of the jabuticaba seed was fixed for further univariate optimization of the extraction time.

\section{Validation of the predicted optimal solvent composition}

The extraction solvent was validated using seven replicates $(n=7)$ under the same conditions previously mentioned, but instead, the optimum solvent mixture was used to extract TPC and TMA from the jabuticaba seed and skin, respectively.

\section{Univariate optimization of extraction time}

The time was the last variable to be optimized using a univariate optimization procedure. At this stage, the optimum solvent mixture conditions for skin and seed were evaluated with the goal of reducing the extraction time. The following times were tested: (i) $2 \mathrm{~h}$ of extraction and $2 \mathrm{~h}$ of re-extraction; (ii) $2 \mathrm{~h}$ of extraction and $1.5 \mathrm{~h}$ of re-extraction; (iii) $2 \mathrm{~h}$ of extraction and $1 \mathrm{~h}$ of re-extraction; (iv) $2 \mathrm{~h}$ of extraction and $30 \mathrm{~min}$ of re-extraction; (v) $1.5 \mathrm{~h}$ of extraction and $30 \mathrm{~min}$ of re-extraction; (vi) $1 \mathrm{~h}$ of extraction and $30 \mathrm{~min}$ of re-extraction; (vii) $30 \mathrm{~min}$ of extraction and 30 min of re-extraction; and (viii) 15 min of extraction and 15 min of re-extraction.

\section{Comparison of the optimized extraction method in this work with other described methods}

The optimal and validated conditions obtained in our study were then compared with the methods described by Alezandro et al. ${ }^{25}$ and by Santos et al. ${ }^{27}$ Three independent replicates were performed for each experiment.

\section{Procedure for TMA from jabuticaba skin extracts}

TMA content was determined by the $\mathrm{pH}$-differential method described by Giusti and Wrosltad. ${ }^{28}$ The method consists of two dilutions of the sample in two buffer systems: potassium chloride, $\mathrm{pH} 1.0\left(0.025 \mathrm{~mol} \mathrm{~L}^{-1}\right)$, and sodium acetate, $\mathrm{pH} 4.5\left(0.4 \mathrm{~mol} \mathrm{~L}^{-1}\right)$.

The dilution factor for the samples was determined using potassium chloride buffer, $\mathrm{pH} 1.0$, until the absorbance of the sample at the maximum wavelength $(520 \mathrm{~nm})$ did not exceed 1.2. Two dilutions of the sample were prepared, one with potassium chloride buffer, $\mathrm{pH} 1.0$, and one with sodium acetate buffer, $\mathrm{pH} 4.5$; both had the same dilution factor. Samples were left to stabilize for $15 \mathrm{~min}$, and the readings were taken at 520 and $700 \mathrm{~nm}$ wavelengths.

Sample absorbance and TMA concentration were calculated according to Giusti and Wrosltad. ${ }^{28}$ TMA samples were expressed in mg equivalent of cyanidin-3-glycoside per $100 \mathrm{~g}$ of freeze-dried sample (mg c-3-g $100 \mathrm{~g}^{-1}$ d.w.).

\section{Procedure for TPC from jabuticaba seed extracts}

Seed TPC was determined according to the FolinCiocalteu method adapted by Singleton et al..$^{29}$ An aliquot of $25 \mu \mathrm{L}$ of sample was added to $125 \mu \mathrm{L}$ of Folin-Ciocalteu reagent, diluted 1:10 (v/v) in distilled water, and added to the wells of the microplate. After a 5 min wait, $100 \mu \mathrm{L}$ of $7.5 \%$ sodium carbonate solution $(\mathrm{m} / \mathrm{v})$ was added. After $2 \mathrm{~h}$ at room temperature, the sample absorbance was measured at a $760 \mathrm{~nm}$ wavelength. Gallic acid was used as the standard, and the results were expressed in mg equivalents of gallic acid per gram of freeze-dried sample (mg GAE g-1 d.w.). We also decided to employ this procedure to determine TPC in the skin extracts of five more varieties of jabuticaba.

Application of the completely optimized protocols for the analysis of other jabuticaba varieties

Our completely optimized protocols for TMA extraction from jabuticaba skin and TPC extraction from jabuticaba seed were used for the seed and skin extracts of five more jabuticaba varieties, from two crop years (2014 and 2015) and described in the "Samples" sub-section, in order to determine the TPC of the seed extracts and the TMA of the skin extracts of these other varieties. The varieties were "Paulista" (Myrciaria cauliflora (DC.) O. Berg) (PF), "Sabará" (Myrciaria jaboticaba (Vell.) O. Berg) (SFP), "Coroada" (Myrciaria coronata Mattos) (CFP), "Híbrida" (Myrciaria cauliflora (DC.) O. Berg) (HFP) and "Pintada" (Plinia ssp.) (PFP). The extracts were prepared and analyzed in triplicate. We also analyzed TPC contents in the jabuticaba skin extracts, only as an additional information. TPC and TMA procedures were the same as described above and used in the experiments of the optimization sub-section.

Principal component analysis (PCA) and statistical analysis

PCA was used to better exploit the results obtained from the seed TPC and skin TMA analyses. The pre-processing used was autoscaling, and the selected components number was two. The analysis was performed with Matlab ${ }^{30}$ and PLS_Toolbox ${ }^{31}$ softwares.

All data were subjected to the analysis of variance 
(ANOVA), and the means were compared by Tukey's and Student's $t$-tests $(p<0.05)$ using the Statistica 7.0 software. ${ }^{32}$

\section{Results and Discussion}

Optimization of the solvent composition for TPC extraction from jabuticaba seed and TMA extraction from jabuticaba skin

In this study, we used two experimental designs using mixtures of methanol, ethanol and water to optimize the extraction of the jabuticaba seed TPC content (design 1) and the extraction of the jabuticaba skin TMA content (design 2; in this trial, the solvent mixtures were acidified with $0.5 \%$ acetic acid). Table S1 (SI section) provides the full results for optimization of the solvent mixture.

The lowest seed TPC extraction efficiency was recorded for trial 11 (100\% water), followed by trials 9 (50\% ethanol, $50 \%$ methanol), 1 (100\% ethanol), 3 ( $16.6 \%$ ethanol, $16.6 \%$ methanol and $66.6 \%$ water), and 10 (100\% methanol). In contrast, trials 7 (33.3\% ethanol, $33.3 \%$ methanol and $33.3 \%$ water), 8 ( $16.6 \%$ ethanol, $66.6 \%$ methanol and $16.6 \%$ water) and $6(66.6 \%$ ethanol, $16.6 \%$ methanol and $16.6 \%$ water) had the highest extraction efficiencies. However, the best solvent mixture for extracting seed TPC was $60 \%$ ethanol $+40 \%$ water, as seen in the quadratic response model presented in Figure 1 and in the predicted values (Table 1). Morelli and Prado ${ }^{33}$ verified that the best solvent mixture to extract TPC from grapes was $60 \%$ ethanol and $40 \%$ water in an ultrasonic bath. The use of ethanol as a solvent to extract TPC was also reported in other studies. ${ }^{27,34,35}$

Regarding the extraction of skin TMA, trial 11 (100\% water $+0.5 \%$ acetic acid) showed the poorest results, followed by trials $1(100 \%$ ethanol $+0.5 \%$ acetic acid $)$ and
$9(50 \%$ ethanol $+50 \%$ methanol $+0.5 \%$ acetic acid $)$. The best results were obtained in trials 8 (16.6\% ethanol, $66.6 \%$ methanol, $16.6 \%$ water $+0.5 \%$ acetic acid) and $4(33.3 \%$ ethanol, $33.3 \%$ methanol, $33.3 \%$ water $+0.5 \%$ acetic acid). However, to extract skin TMA, the best response was obtained using $80 \%$ methanol $+20 \%$ water acidified with $0.5 \%$ of acetic acid (Figure 1 and Table 1 ).

The methanol:water solvent mixture to extract jabuticaba anthocyanins was also reported by Wu et al., ${ }^{36}$ Alezandro et al. ${ }^{25}$ and Batista et al. ${ }^{37}$ However, in these studies, the solvent mixture optimization was not performed by multivariate design, and consequently the solvent proportions differ from those used in our study, which reports the best solvent mixture for extracting jabuticaba skin TMA.

Experimental validation of the optimal mixtures of solvents predicted in the optimization

To validate the optimized solvent mixtures for extracting TPC and TMA of jabuticaba seed and skin, respectively, we performed 10 extractions $(\mathrm{n}=10)$, using $60 \%$ ethanol $+40 \%$ water for seed and $80 \%$ methanol $+20 \%$ water, acidified with $0.5 \%$ of acetic acid, for skin. All of the obtained results in these extractions were in agreement with the predicted model values and the other parameters as verified by ANOVA (Table 1).

\section{Univariate optimization of the extraction time}

For the optimization of the extraction time trials with jabuticaba seed TPC and jabuticaba skin TMA were performed. For both extractions, 8 options were analyzed, starting with a total of $4 \mathrm{~h}$ (extraction + re-extraction) and decreasing to a total of $30 \mathrm{~min}$ (extraction + re-extraction).
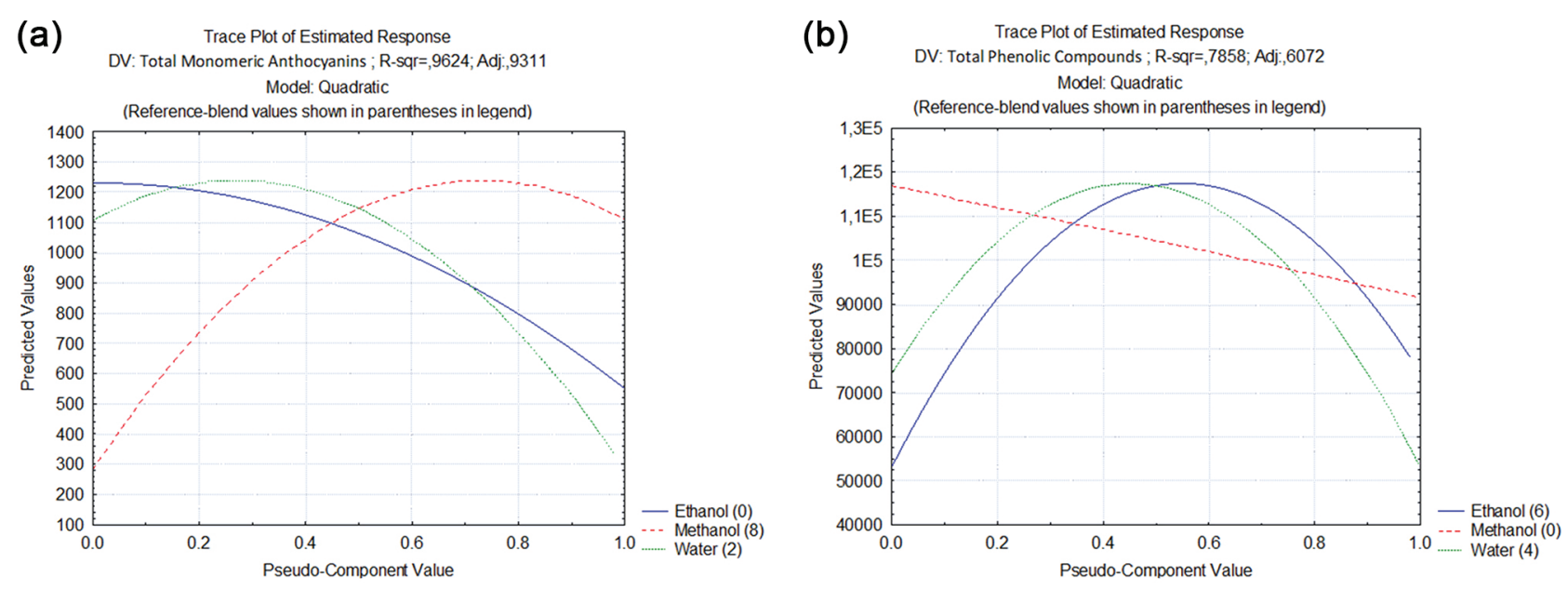

Figure 1. Estimated response graph from the quadratic model. (a) Total monomeric anthocyanins (TMA) from jabuticaba skin; (b) total phenolic compounds (TPC) from jabuticaba seed. 
Table 1. Summary of ANOVA, significant coefficients and validation of prediction for the models calculated in the optimization step

\begin{tabular}{|c|c|c|c|c|c|c|c|c|c|}
\hline \multirow{2}{*}{ Response } & \multirow{2}{*}{$\begin{array}{l}\text { Indicated } \\
\text { model }\end{array}$} & \multicolumn{6}{|c|}{ Significant coefficient \pm standard error } & \multirow{2}{*}{$\begin{array}{c}\text { Regression } \\
\text { significance } \\
(p<0.05)\end{array}$} & \multirow{2}{*}{$\begin{array}{l}\text { Model fit } \\
(p>0.05)\end{array}$} \\
\hline & & A (ethanol) & B (methanol) & $\mathrm{C}$ (water) & $\mathrm{AB}$ & $\mathrm{AC}$ & $\mathrm{BC}$ & & \\
\hline $\begin{array}{l}\text { Total phenolic } \\
\text { compounds }\end{array}$ & quadratic & $\begin{array}{c}74355.2 \pm \\
13328.5 \\
\end{array}$ & $\begin{array}{c}91603.4 \pm \\
13328.5 \\
\end{array}$ & $\begin{array}{c}53099.4 \pm \\
13328.5 \\
\end{array}$ & - & $\begin{array}{c}212839.9 \pm \\
59617.9\end{array}$ & $\begin{array}{c}159410.9 \pm \\
59617.9\end{array}$ & 0.0497 & 0.055 \\
\hline $\begin{array}{l}\text { Total } \\
\text { monomeric } \\
\text { anthocyanins }\end{array}$ & quadratic & $\begin{array}{c}549.76 \pm \\
74.10\end{array}$ & $\begin{array}{c}1107.41 \pm \\
74.10\end{array}$ & $\begin{array}{c}283.50 \pm \\
74.10\end{array}$ & - & $\begin{array}{l}2574.83 \pm \\
331.45\end{array}$ & $\begin{array}{c}1797.58 \pm \\
331.45\end{array}$ & 0.000334 & 0.143 \\
\hline
\end{tabular}
anthocyanins

Validation of the model prediction for the two quadratic models obtained from simplex lattice design in solvent optimization experiments

\begin{tabular}{lll}
\hline Ethanol & Methanol Water & TPC $/\left(\mathrm{mg}\right.$ of gallic acid equivalent $\mathrm{g}^{-1}$ freeze-dried sample (seed))
\end{tabular}

\begin{tabular}{|c|c|c|c|c|c|c|}
\hline \multirow{2}{*}{$\mathrm{X}_{1}$} & \multirow{2}{*}{$\mathrm{X}_{2}$} & \multirow{2}{*}{$\mathrm{X}_{3}$} & \multirow{2}{*}{ Predicted value } & \multicolumn{2}{|c|}{ Interval of confidence } & \multirow{2}{*}{ Experimental value } \\
\hline & & & & $-95 \%$ & $95 \%$ & \\
\hline 0.6 & 0 & 0.4 & 116.93 & 89.25 & 144.61 & $105.35 \pm 4.60$ \\
\hline Ethanol & Methanol & Water & \multicolumn{4}{|c|}{ TMA / (mg of cyanidin-3-glycoside equivalent $100 \mathrm{~g}^{-1}$ freeze-dried sample (skin)) } \\
\hline \multirow{2}{*}{$\mathrm{X}_{1}$} & \multirow{2}{*}{$\mathrm{X}_{2}$} & \multirow{2}{*}{$\mathrm{X}_{3}$} & \multirow{2}{*}{ Predicted value } & \multicolumn{2}{|c|}{ Interval of confidence } & \multirow{2}{*}{ Experimental value } \\
\hline & & & & $-95 \%$ & $95 \%$ & \\
\hline 0 & 0.8 & 0.2 & 1230.23 & 1094.85 & 1365.61 & $1487.64 \pm 24.42$ \\
\hline
\end{tabular}

TPC: total phenolic compounds; TMA: total monomeric anthocyanins; $\mathrm{X}_{1}-\mathrm{X}_{3}$ : proportion of ethanol, methanol and water, respectively.

All experimental conditions were fixed except the time. The results for optimization of the extraction time are presented in Table 2.

The extraction of jabuticaba seed TPC and skin TMA was not statistically and significantly different by Tukey's test; the extraction process that was performed for $4 \mathrm{~h}$ had the same efficiency as that performed for $30 \mathrm{~min}$. With these results, it was possible to reduce the extraction time in $3.5 \mathrm{~h}$, which is excellent and saves the analyst's time and decreases both the electric energy expenditures and equipment wear. It should be noted that the method optimized in this research study is an excellent alternative for researchers that are working with anthocyanins and phenolic compounds because most of the methods found in the literature are usually very long.

Thus, the extraction procedure and optimized time were as follows: $0.5 \mathrm{~g}$ of freeze-dried sample (seed or skin) were weighed, and $50 \mathrm{~mL}$ of ethanol/water extractive solution (60:40, v/v, for phenolic compounds) were added. This extract was shaken for $15 \mathrm{~min}$ in a shaker at $150 \mathrm{rpm}$ at $30{ }^{\circ} \mathrm{C}$. The residue was re-extracted once more in $50 \mathrm{~mL}$ of extractive solution for $15 \mathrm{~min}$. The skin anthocyanin content extraction followed the same procedure described above using methanol/water/acetic acid (80:20:0.5, v/v/v) as the extractive solution. The extracts were centrifuged at $1614.95 \mathrm{~g}$ for $10 \mathrm{~min}$ and filtered on Whatman paper No. 1 ,

Table 2. Univariate optimization of extraction time

\begin{tabular}{|c|c|c|c|}
\hline \multirow[b]{2}{*}{ Extraction time } & \multirow[b]{2}{*}{$\begin{array}{c}\text { Re-extraction } \\
\text { time }^{\mathrm{a}}\end{array}$} & \multicolumn{2}{|c|}{ Extraction yield ${ }^{\mathrm{b}}$} \\
\hline & & $\begin{array}{l}\text { Total phenolic compounds / } \\
\text { (mg of gallic acid equivalent } \mathrm{g}^{-1} \\
\text { freeze-dried sample (seed)) }\end{array}$ & $\begin{array}{l}\text { Total monomeric anthocyanins / } \\
\text { (mg of cyanidin-3-glycoside equivalent } 100 \mathrm{~g}^{-1} \\
\text { freeze-dried sample (skin)) }\end{array}$ \\
\hline $2 \mathrm{~h}$ & $2 \mathrm{~h}$ & $113.05 \pm 4.55 \mathrm{a}$ & $1267.26 \pm 43.23 \mathrm{a}$ \\
\hline $2 \mathrm{~h}$ & $1.5 \mathrm{~h}$ & $116.17 \pm 7.10 \mathrm{a}$ & $1244.07 \pm 58.49 \mathrm{a}$ \\
\hline $2 \mathrm{~h}$ & $1 \mathrm{~h}$ & $113.53 \pm 6.31 \mathrm{a}$ & $1275.15 \pm 34.37 \mathrm{a}$ \\
\hline $2 \mathrm{~h}$ & $30 \mathrm{~min}$ & $109.55 \pm 0.69 \mathrm{a}$ & $1285.81 \pm 83.63 \mathrm{a}$ \\
\hline $1.5 \mathrm{~h}$ & $30 \mathrm{~min}$ & $101.31 \pm 3.81 \mathrm{a}$ & $1065.48 \pm 36.32 \mathrm{a}$ \\
\hline $1 \mathrm{~h}$ & $30 \mathrm{~min}$ & $96.26 \pm 5.02 \mathrm{a}$ & $1063.16 \pm 26.44 \mathrm{a}$ \\
\hline $30 \mathrm{~min}$ & $30 \mathrm{~min}$ & $102.20 \pm 2.07 \mathrm{a}$ & $1103.05 \pm 16.60 \mathrm{a}$ \\
\hline $15 \mathrm{~min}$ & $15 \mathrm{~min}$ & $89.15 \pm 3.34 \mathrm{a}$ & $1113.26 \pm 33.13 \mathrm{a}$ \\
\hline
\end{tabular}

${ }^{a} \mathrm{Re}$-extraction procedure is performed once; ${ }^{b}$ results are mean values $(\mathrm{n}=3) \pm$ standard deviations. The same lowercase letter in the columns means no significant differences at $95 \%$ of confidence $(p \leq 0.05)$ by Tukey's test. 
and the filtrates were combined and calibrated to a volume of $100 \mathrm{~mL}$ in a volumetric flask.

\section{Comparison of the optimized extraction method with other methods reported in the literature}

In this study, the "Sabará" jabuticaba seed TPC and skin TMA were extracted using three extraction methods: the optimized method, the method described by Alezandro et al. ${ }^{25}$ and the method described by Santos et al. ${ }^{27}$ All results for these analyses are shown in Table 3.

The optimized extraction method in this study was not significantly different $\left(89.15 \mathrm{mg} \mathrm{GAE} \mathrm{g}^{-1}\right.$ d.w. TCP, $1113.26 \mathrm{mg} \mathrm{c}^{-3}$-g $100 \mathrm{~g}^{-1}$ d.w. TMA) compared to that proposed by Alezandro et al..$^{25}$ (89.53 $\mathrm{mg} \mathrm{GAE} \mathrm{g}^{-1}$ d.w. TCP, $1359.10 \mathrm{mg} \mathrm{c}^{-3}-\mathrm{g} 100 \mathrm{~g}^{-1}$ d.w. TMA). However, the optimized method is more advantageous because it is extremely fast, taking only $30 \mathrm{~min}$ to perform the extraction instead of $6 \mathrm{~h}$. Another great advantage is that for extraction of TPC from seed, researchers can use ethanol:water $(60: 40, \mathrm{v} / \mathrm{v})$ as the extractive solvent, while Alezandro et al. ${ }^{25}$ used methanol:water $(70: 30, \mathrm{v} / \mathrm{v})$, because ethanol is less toxic than methanol and is thus less risky to the analyst and the environment.

The extraction method proposed by Santos et al. ${ }^{27}$

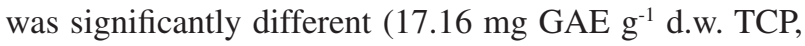
$77.34 \mathrm{mg} \mathrm{c}-3-\mathrm{g} 100 \mathrm{~g}^{-1}$ d.w. TMA) compared to the optimized method in this study and the method recommended by Alezandro et al. ${ }^{25}$ The last two methods had efficiency higher than $80 \%$ for extracting phenolic compounds and $93 \%$ efficiency in extracting anthocyanins; the optimized method reduces the extraction time in $1.5 \mathrm{~h}$.

Keeping these results in mind, the optimized extraction methods proved to be an excellent method for extracting the seed TPC and skin TMA from jabuticaba fruit; the methods had high efficiency for extracting the compounds of interest, is extremely fast, practical and simple, and uses solvents and equipment found in most research laboratories.

\section{TPC and TMA evaluated in five jabuticaba varieties}

The optimized extraction protocols validated in our study were applied to obtain extracts of skin and seed of five other jabuticaba varieties (SFP, PF, CFP, HFP and PFP), harvested in two crop seasons (2014 and 2015), totalling 24 samples. The TPC of the seed extracts and the TMA of the skin extracts were then analyzed for all these varieties, using the same procedures used to analyze the extracts of the optimization experiments. We also decided to analyze the TPC present in the skin extracts obtained by our protocol, as an additional information, because jabuticaba skin can also present other phenolic compounds apart from the anthocyanins, which are the main components. The obtained results for all these varieties are presented in Table 4 and Figure 2.

The data presented in Table 4 were used for PCA. The data were arranged in a $36 \times 3$ dimension matrix with the samples in the 36 rows and the variables in the 3 columns. The 36 rows correspond to the triplicates for the measured variables in the varieties in both crops (2014 and 2015).

Table 3. Comparison of the three extraction methods

\begin{tabular}{|c|c|c|c|c|}
\hline Extraction time & $\begin{array}{l}\text { Re-extraction } \\
\text { time }\end{array}$ & Solvent extractor & $\begin{array}{c}\text { Condition of the extraction } \\
\text { process }\end{array}$ & Yield $^{\mathrm{a}}$ \\
\hline \multicolumn{5}{|c|}{ Optimized extraction (this study) } \\
\hline $15 \mathrm{~min}$ & $15 \mathrm{~min}$ & ethanol/water $(60: 40, \mathrm{v} / \mathrm{v})$ & & $89.15 \pm 3.34 \mathrm{a} \mathrm{TCP}$ \\
\hline $15 \mathrm{~min}$ & $15 \mathrm{~min}$ & $\begin{array}{c}\text { methanol/water/acetic acid } \\
(80: 20: 0.5, \mathrm{v} / \mathrm{v} / \mathrm{v})\end{array}$ & shaking at $150 \mathrm{rpm}$ at $30^{\circ} \mathrm{C}$ & $1113.26 \pm 33.13 \mathrm{~A} \mathrm{TMA}^{\circ}$ \\
\hline \multicolumn{5}{|c|}{ Extraction according to Alezandro et al. ${ }^{25}$} \\
\hline $2 \mathrm{~h}$ & $2 \mathrm{~h} \times 2 \mathrm{~h}$ & methanol/water $(70: 30, \mathrm{v} / \mathrm{v})$ & & $89.53 \pm 1.49 \mathrm{a} \mathrm{TCP}$ \\
\hline $2 \mathrm{~h}$ & $2 \mathrm{~h} \times 2 \mathrm{~h}$ & $\begin{array}{c}\text { methanol/water/acetic acid } \\
\text { solution }(70: 30: 0.5, \mathrm{v} / \mathrm{v} / \mathrm{v})\end{array}$ & shaking at $150 \mathrm{rpm}$ at $30^{\circ} \mathrm{C}$ & $1359.10 \pm 50.25 \mathrm{~A} \mathrm{TMA}^{\mathrm{c}}$ \\
\hline \multicolumn{5}{|c|}{ Extraction according to Santos et al..$^{27}$} \\
\hline $2 \mathrm{~h}$ & - & pure ethanol & $\begin{array}{l}\text { sonicated for } 10 \mathrm{~min} \text {; after } \\
\text { incubation in a shaking bath }\end{array}$ & $17.16 \pm 2.36 \mathrm{~b} \mathrm{TCP}^{\mathrm{b}}$ \\
\hline $2 \mathrm{~h}$ & - & pure ethanol & at $150 \mathrm{rpm}$ at $30^{\circ} \mathrm{C}$ & $77.34 \pm 8.67 \mathrm{~B} \mathrm{TMA}^{\mathrm{c}}$ \\
\hline
\end{tabular}

Results are mean values $(\mathrm{n}=3) \pm$ standard deviations. The same lowercase letters represent no significant differences between the total phenolic compounds contents, the same capital letters represent no significant differences between total anthocyanins monomeric contents (at $95 \%$ of confidence ( $p \leq 0.05$ ) by Tukey's test); btotal phenolic compounds contents expressed as mg of gallic acid equivalent $\mathrm{g}^{-1}$ freeze-dried sample; 'total monomeric anthocyanins contents expressed as mg of cyanidin-3-glycoside equivalent $100 \mathrm{~g}^{-1}$ freeze-dried sample. TPC: total phenolic compounds; TMA: total monomeric anthocyanins. 
Table 4. Content of total monomeric anthocyanins from skin and total phenolic compounds from seed of jabuticaba $($ mean \pm standard deviations, $\mathrm{n}=3$ )

\begin{tabular}{|c|c|c|c|c|c|c|}
\hline \multirow{3}{*}{ Variety } & \multirow{2}{*}{\multicolumn{2}{|c|}{ 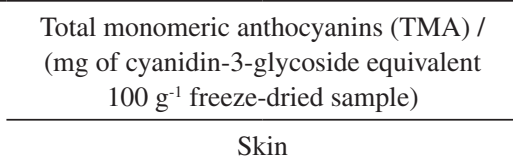 }} & \multicolumn{4}{|c|}{$\begin{array}{c}\text { Total phenolic compounds (TPC) / } \\
\text { (mg of gallic acid equivalent } \mathrm{g}^{-1} \text { freeze-dried sample) }\end{array}$} \\
\hline & & & \multicolumn{2}{|c|}{ Skin } & \multicolumn{2}{|c|}{ Seed } \\
\hline & 2014 & 2015 & 2014 & 2015 & 2014 & 2015 \\
\hline $\begin{array}{l}\text { "Sabará" Fagan } \\
\text { (SF) }\end{array}$ & $1172.16 \pm 25.52 \mathrm{~B} \mathrm{~d}$ & $2510.39 \pm 18.19 \mathrm{~A} \mathrm{~b}$ & $82.13 \pm 1.34 \mathrm{~B} \mathrm{~b}$ & $103.23 \pm 3.28 \mathrm{~A} \mathrm{c}$ & $86.50 \pm 2.51 \mathrm{~B} \mathrm{~b} \mathrm{c}$ & $95.77 \pm 3.57 \mathrm{~A} \mathrm{c}$ \\
\hline $\begin{array}{l}\text { "Paulista" Fagan } \\
(\mathrm{PF})\end{array}$ & $273.67 \pm 18.99 \mathrm{~B} \mathrm{e}$ & $481.02 \pm 23.71 \mathrm{~A} \mathrm{e}$ & $75.91 \pm 2.74 \mathrm{~B} \mathrm{~b} \mathrm{c}$ & $94.10 \pm 1.51 \mathrm{~A} \mathrm{c}$ & $72.05 \pm 2.52 \mathrm{~B} \mathrm{~d}$ & $119.18 \pm 0.80 \mathrm{~A} \mathrm{a} \mathrm{b}$ \\
\hline $\begin{array}{l}\text { "Sabará” F. P. } \\
\text { (SFP) }\end{array}$ & $1603.09 \pm 110.20 \mathrm{~B} \mathrm{c}$ & $2892.15 \pm 58.35 \mathrm{~A} \mathrm{a}$ & $122.78 \pm 4.15 \mathrm{~B} \mathrm{a}$ & $141.63 \pm 5.59 \mathrm{~A} \mathrm{a}$ & $95.39 \pm 4.74 \mathrm{~B} \mathrm{~b}$ & $112.13 \pm 7.29 \mathrm{~A} \mathrm{~b}$ \\
\hline $\begin{array}{l}\text { "Híbrida" F. P. } \\
\text { (HFP) }\end{array}$ & $1098.49 \pm 22.41 \mathrm{~B} \mathrm{~d}$ & $1498.72 \pm 13.70 \mathrm{~A} \mathrm{c}$ & $71.232 \pm 0.93 \mathrm{~B} \mathrm{c}$ & $120.45 \pm 4.85 \mathrm{~A} \mathrm{~b}$ & $72.24 \pm 1.61 \mathrm{~B} \mathrm{~d}$ & $109.74 \pm 8.19 \mathrm{~A} \mathrm{~b} \mathrm{c}$ \\
\hline $\begin{array}{l}\text { "Pintada" F. P. } \\
\text { (PFP) }\end{array}$ & $1801.90 \pm 1.76 \mathrm{~B} \mathrm{~b}$ & $947.19 \pm 48.69 \mathrm{~A} \mathrm{~d}$ & $55.27 \pm 2.58 \mathrm{~B} \mathrm{~d}$ & $147.88 \pm 0.37 \mathrm{~A} \mathrm{a}$ & $78.17 \pm 4.56 \mathrm{~B} \mathrm{c} \mathrm{d}$ & $117.08 \pm 4.21 \mathrm{~A} \mathrm{a} \mathrm{b}$ \\
\hline $\begin{array}{l}\text { "Coroada" F. P. } \\
\text { (CFP) }\end{array}$ & $2059.57 \pm 3.42 \mathrm{~B} \mathrm{a}$ & $1398.06 \pm 44.49 \mathrm{~A} \mathrm{c}$ & $127.81 \pm 6.33 \mathrm{~A} \mathrm{a}$ & $127.03 \pm 4.33 \mathrm{~A} \mathrm{~b}$ & $125.96 \pm 4.17 \mathrm{~A} \mathrm{a}$ & $131.62 \pm 4.13 \mathrm{~A} \mathrm{a}$ \\
\hline
\end{tabular}

The same capital letters represent equal means in the lines (comparison between harvesting years, $p<0.05$ ), and the same lowercase letters represent equal averages in the columns (between different varieties for each harvest year, $p<0.05$ ). Tukey's $p \leq 0.05, \mathrm{n}=3$.
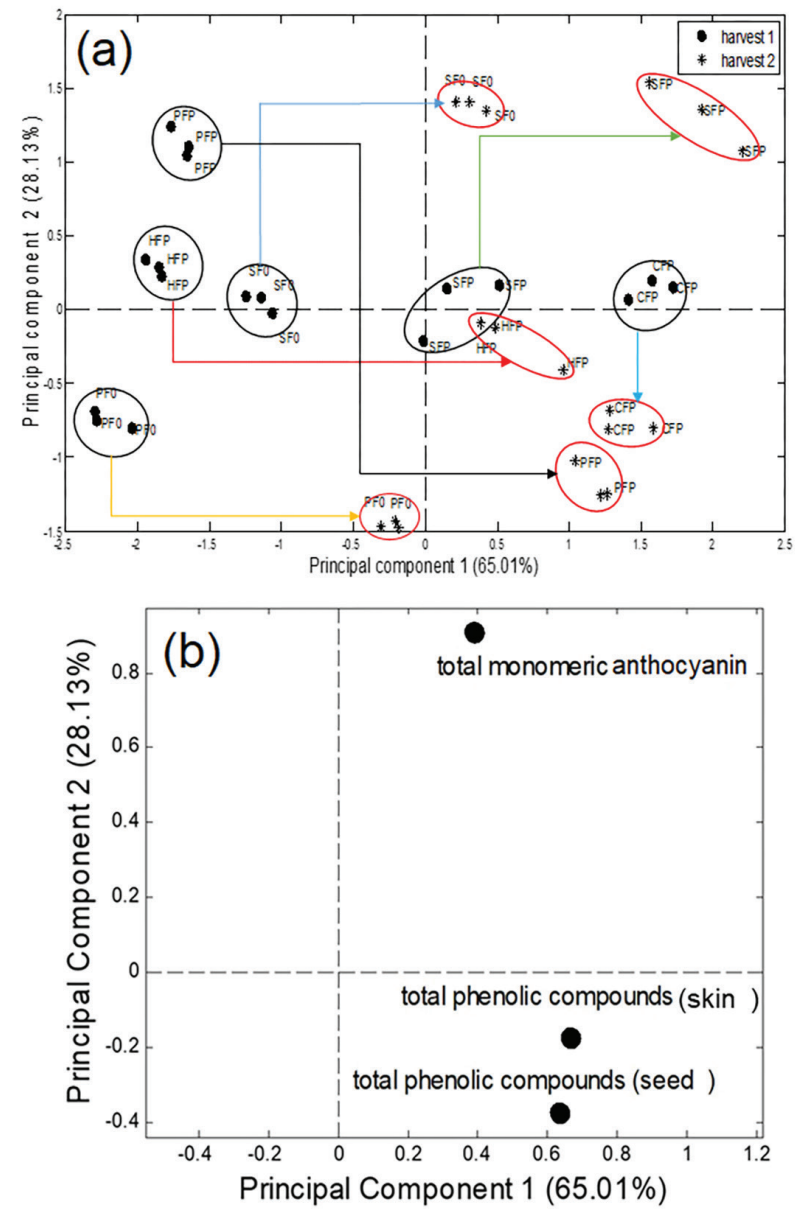

Figure 2. (a) Score graph for jabuticaba varieties: SF0, "Sabará" Fagan; PF, "Paulista"; SFP, "Sabará" F. P.; PFP, "Pintada"; HFP, "Híbrida"; and CFP, "Coroada"; crop 1 samples (2014) and * crop 2 samples (2015). (b) Loadings graph for principal components analysis.
The varieties are described by abbreviation in the PCA scores graph, and the symbols describe the two crops. The variables used for exploratory analysis were the TMA of the skin and TPC of the seed and skin. Although the number of variables in this stage of the study was not high, the use of PCA allowed a better visualization of the data in a twodimensional graph $(\mathrm{PC} 1 \times \mathrm{PC} 2)$, thus justifying its use. The loadings graph showed how each variable influenced the position of the samples in the score graph. All samples remained in the model since outlier samples were not found.

Analyzing the scores graph using the 2014 and 2015 crop seasons (Figure 2a) together, the loadings graph (Figure $2 \mathrm{~b}$ ) and the data in Table 4 verify that the skin and seed TPC are the variables that were most highly positively correlated with PC1, but the loadings were not very high (approximately 0.6-0.7).

Regarding PC2, the most correlated variable was skin TMA, with a considerably high loading (greater than 0.9). Comparing the two crop seasons, practically all the samples had a higher content of skin and seed TPC in the 2015 crop, indicating that the levels of TPC and skin TMA in jabuticabas are strongly influenced by the crop season due to several environmental factors, such as rainfall, drought, temperature, soil conditions and others.

The results obtained in the varieties of the CFP and PFP seed, both of the 2015 harvest, and the PFP and SFP skin also belonging to the 2015 harvest, were those with the highest concentration of total phenolic compounds when compared to the other varieties studied here. SF and SFP jabuticabas harvested in 2015 were the samples with the 
highest anthocyanin content. The HFP jabuticaba harvested in 2015 had more phenolic compounds in its skin than in its seed, whereas the CFP jabuticaba harvested in 2015 had considerably higher values of phenolic compounds in skin and seed. In contrast, the PFP jabuticaba harvested in 2015 was verified to have the lowest anthocyanin content. However, a higher concentration of phenolic compounds was found in skin and seed.

PFP jabuticaba harvested in 2014, compared to the SF and SFP jabuticabas harvested in 2015, had considerably lower anthocyanin content, and similar results were verified for the HFP jabuticaba harvested in 2014. The SF jabuticaba harvested in 2014 had a lower concentration of phenolic compounds in its skin and seed and lower concentration of anthocyanins in comparison to the SFP and CFP jabuticaba fruits harvested in 2014. Regarding the results found for PF jabuticaba, in both crop seasons (2014 and 2015), this variety had the lowest content of phenolic compounds and anthocyanins in comparison to the other varieties analyzed in this study.

In addition, there are studies on only "Sabará" and "Paulista" jabuticabas varieties. The "Pintada", "Híbrida" and "Coroada" jabuticabas varieties have not been studied to date, and this first work investigates these varieties.

Hacke et al. ${ }^{18}$ reported $8.65 \mathrm{~g} \mathrm{GAE} 100 \mathrm{~g}^{-1}$ d.w. in "Paulista" jabuticaba seed, a result that is in agreement with this study for "Paulista" jabuticaba harvested in the 2014

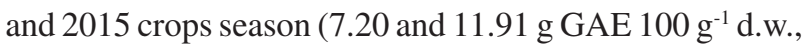
respectively).

In contrast, for the "Sabará" and "Paulista" jabuticabas, it was reported that the skin TMA contents were 350 and 450 mg c-3-g $100 \mathrm{~g}^{-1}$ d.w., respectively. ${ }^{25}$ However, these results are lower than those found in the present study for the same variety: 1172.16 and $2510.39 \mathrm{mg} \mathrm{c}-3$-g $100 \mathrm{~g} \mathrm{~g}^{-1}$ d.w., in 2014 and 2015 crop seasons, respectively, and 373.67 and $481.02 \mathrm{mg} \mathrm{c}-3-\mathrm{g} 100 \mathrm{~g}^{-1} \mathrm{~d}$.w. for the 2014 and 2015 crops, respectively.

Santos et al. ${ }^{27}$ reported TPC and anthocyanin contents of $33.97 \mathrm{mg} \mathrm{GAE} \mathrm{g}^{-1}$ d.w. and $533 \mathrm{mg} \mathrm{c}-3$-g $100 \mathrm{~g} \mathrm{~g}^{-1}$ d.w., respectively, in jabuticaba skin. For "Sabará" jabuticaba, Batista et al. ${ }^{37}$ found a TPC value of $113.80 \mathrm{mg} \mathrm{GAE} \mathrm{g}^{-1}$ d.w. and a TMA value of $1737.12 \mathrm{mg} \mathrm{c}-3-\mathrm{g} 100 \mathrm{~g}^{-1}$ d.w., corroborating the results obtained in this study for the 2014 crop season. However, for the 2015 crop season, the results were higher than those recorded in 2014. It is probable that the results were influenced by the changes in growing and environmental conditions in both crop seasons. For "Sabará" jabutica skin, Silva et al..$^{38}$ reported total

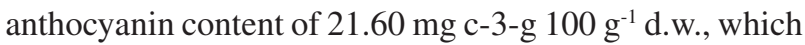
was lower than the one found in this study, which again confirms the efficiency of the extraction method used here.
All analyzed varieties in this study had considerably higher concentrations of TPC and TMA, and these results are very important since phenolic compounds are extremely beneficial to health.

\section{Conclusions}

Using ternary mixture designs, we were able to optimize the extraction solvent composition for the obtainment of jabuticaba seed extracts with the highest content of TPC and jabuticaba skin extracts with the highest TMA content. The mixture for extracting TPC from jabuticaba seed consisted in ethanol:water $(60: 40, \mathrm{v} / \mathrm{v})$. For the TMA extraction from jabuticaba skin, the mixture consisted in metanol:water $(80: 20, \mathrm{v} / \mathrm{v})$, with an additional $0.5 \%$ $(\mathrm{v} / \mathrm{v})$ of acetic acid. Subsequently, using our optimized solvents, we also achieved the extraction time reduction from $4 \mathrm{~h}$ to $30 \mathrm{~min}$, for both jabuticaba skin and seed, with no difference in the TMA and TPC contents obtained. In comparison with other two extraction methods presented in the literature, our protocols reduced the extraction time, and thus reduced expenses with energy supply, equipment, and analyst time. Our optimized protocols also had high efficiency for extracting phenolic compounds from seed and anthocyanins from skin of five jabuticaba varieties available in Brazil.

\section{Supplementary Information}

Supplementary data (results for the experimental designs) are available free of charge at http://jbcs.sbq.org.br as PDF file.

\section{Acknowledgments}

The authors are thankful to Coordenação Nacional de Desenvolvimento Científico e Tecnológico (CNPq; process No. 145652/2014-9) for its financial support for this study; to Coordenação de Aperfeiçoamento de Pessoal de Nível Superior (CAPES Foundation, Brazil) for the financial assistance provided to the research laboratory; and to Luciana Fontes de Oliveira for collaborating in the principal component analysis (PCA).

\section{References}

1. Silva, S. P.; Frutas no Brasil; Nobel: São Paulo, 2001.

2. Abe, L. T.; Lajolo, F. M.; Genovese, M. I.; J. Sci. Food Agric. 2012, 92, 1679.

3. Leite-Legatti, A. V.; Batista, A. G.; Dragano, N. R. V.; Marques, A. C.; Malta, L. G.; Riccio, M. F.; Eberlin, M. N.; Machado, A. 
R. T.; Carvalho-Silva, L. B.; Ruiz, A. L. T. G.; Carvalho, J. E.; Pastore, G. M.; Maróstica Jr., M. R.; Food Res. Int. 2012, 49, 596.

4. Silva, F. J. G.; Aliment. Nutr. 2010, 21, 429.

5. Lima, A. J. B.; Corrêa, A. D.; Alves, A. P. C.; Abreu, C. M. P.; Dantas-Barros, A. M.; Arch. Latinoam. Nutr. 2008, 58, 416.

6. Xie, X.; Zhao, R.; Shen, G. X.; J. Agric. Food Chem. 2012, 60, 1850.

7. Szajdek, A.; Borowska, E. J.; Plant Foods Hum. Nutr. 2008, $63,147$.

8. Gorinstein, S.; Kulasek, G. W.; Bartnikowska, E.; Leontowicz, M.; Zemser, M.; Morawiec, M.; Trakhtenberg, S.; Food Chem. 2000, 70, 303.

9. Prata, A.; Brunton, N. P.; O'Donnell, C.; Tiwari, B. K.; Trends Food Sci. Technol. 2010, 21, 3.

10. Buchweitz, M.; Brauch, J.; Carle, R.; Kammerer, D. R.; Food Res. Int. 2013, 138, 2026.

11. Youdim, K. A.; McDonald, J.; Kalt, W.; Joseph, J. A.; J. Nutr. Biochem. 2002, 13, 282.

12. Hou, D. X.; Curr. Mol. Med. 2003, 3, 149.

13. Peterson, J.; Dwyer, J.; Nutr. Res. 1998, 18, 1995.

14. Zhao, C.; Giusti, M. M.; Malik, M.; Moyer, M. P.; Magnuson, B. A.; J. Agric. Food Chem. 2004, 52, 6122.

15. Kapadia, G. J.; Balasubramanian, V.; Tokuda, H. I.; Washina, A.; Nishino, H.; Cancer Lett. 1997, 115, 173.

16. Zhang, Y.; Seeram, N. P.; Lee, R.; Feng, L.; Heber, D.; J. Agric. Food Chem. 2008, 56, 670.

17. Zou, T. B.; Wang, M.; Gan, R. Y.; Ling, W. H.; Int. J. Mol. Sci. 2011, 12, 3006.

18. Hacke, A. C. M.; Granato, D.; Maciel, L. G.; Weinert, P. L.; Prado-Silva, L.; Alvarenga, V. O.; Sant'Ana, A. S.; Bataglion, G. A.; Eberlin, M. N.; Rosso, N. D.; J. Food Sci. 2016, 81, 2206.

19. Dai, J.; Mumper, R.; Molecules 2010, 15, 7313.

20. Ferreira, S. L. C.; Bruns, R. E.; da Silva, E. G. P.; dos Santos, W. N. L.; Quintella, C. M.; David, J. M.; de Andrade, J. B.; Breitkreitz, M. C.; Jardim, I. C. S. F.; Barros Neto, B.; J. Chromatogr. A 2007, 1158, 2.

21. Aaby, K.; Mazur, S.; Nes, A.; Skrede, G.; Food Chem. 2012, 132, 86.
22. Escríbano-Bailón, T. M.; Santos-Buelga, C. In Methods in Polyphenol Analysis; Saltmarsh, M.; Santos-Buelga, C.; Williamson, G., eds.; Royal Society of Chemistry: Cambridge, 2003.

23. Vagiri, M.; Ekholm, A.; Andersson, S. C.; Johansson, E.; Rumpunen, K.; J. Agric. Food Chem. 2012, 60, 10501.

24. Zheng, J.; Yang, B.; Ruusunen, V.; Laaksonen, O.; Tahvonen, R.; Hellsten, J.; Kallio, H.; J. Agric. Food Chem. 2012, 60, 6581.

25. Alezandro, M. R.; Dubé, P.; Desjardins, Y.; Lajolo, F. M.; Genovese, M. I.; Food Res. Int. 2013, 54, 468.

26. Bochi, V. C.; Barcia, M. T.; Rodrigues, D.; Speroni, C. S.; Giusti, M. M.; Godoy, H. T.; Food Chem. 2014, 164, 347.

27. Santos, T. D.; Veggi, C. P.; Meireles, A. A. M.; J. Food Eng. 2010, 101, 23.

28. Giusti, M. M.; Wrolstad, R. E. In Current Protocols in Food Analytical Chemistry; Wrolstad, R. E., ed.; John Wiley \& Sons: New York: 2001, unit F1.2.1-13.

29. Singleton, V. L.; Orthofer, R.; Lamuela-Raventos, R. M.; Methods Enzymol. 1999, 299, 152.

30. MathWorks; Matlab version R2014a; MathWorks, USA, 2014.

31. Eigenvector; PLS_Toolbox version 7.3.1; Eigenvector, USA, 2013.

32. StatSoft Inc.; Statistica version 7.0; StatSoft, USA, 2004.

33. Morelli, L. L. L.; Prado, M. A.; Ultrason. Sonochem. 2012, 19, 1144.

34. Ribeiro, A. B.; Berto, A.; Chisté, R. C.; Freitas, M.; Visentainer, J. V.; Fernandes, E.; Pharm. Biol. 2015, 53, 1267.

35. Berto, A.; Ribeiro, A. B.; de Souza, N. E.; Fernandes, E.; Chisté, R. C.; Food Res. Int. 2015, 77, 236.

36. Wu, S.; Dastmalchi, K.; Long, C.; Kennelly, E. J.; J. Agric. Food Chem. 2012, 60, 7513.

37. Batista, A. G.; Lenquiste, S. A.; Cazarin, C. B. B.; da Silva, J. K.; Luiz-Ferreira, A.; Bogusz Jr., S.; Hantao, L. W.; de Souza, R. N.; Augusto, F.; Prado, M. A.; Maróstica Jr., M. R.; J. Funct. Foods 2014, 6, 450.

38. Silva, M. C.; de Souza, V. B.; Thomazini, M.; da Silva, E. R.; Smaniotto, T.; de Carvalho, R. A.; Genovese, M. I.; FavaroTrindade, C. S.; LWT--Food Sci. Technol. 2014, 55, 203.

Submitted: December 13, 2018

Published online: March 26, 2019 